\title{
"Criar novas ideias a partir de músicas prontas": reflexões, experiências e aprendizagens na produção de mashup
}

JUCIANE ARALDI BELTRAME

Juciane Araldi Beltrame é docente do Departamento de Educação Musical da Universidade Federal da Paraíba (UFPB). Doutora em Música - Música e Educação na Universidade Federal do Estado do Rio de Janeiro (UNIRIO). Mestre em Música - Educação Musical - pela Universidade Federal do Rio Grande do Sul (UFRGS). Especialista em Medotologia do Ensino da Arte pela Universidade Tuiuti do Paraná (UTP). Licenciada nos cursos de Licenciatura em Música da Escola de Música e Belas Artes do Paraná (EMBAP) e Educação Artística pela Universidade Federal do Paraná (UFPR). Atua na área de Educação Musical nas temáticas: práticas musicais de DJs, música eletrônica, hip hop, formação docente, educação musical e tecnologia, educação musical online. (<http://lattes.cnpq.br/1575444703062327>)

AFILIAÇÃO: Universidade Federal da Paraíba (UFPB), João Pessoa, Paraíba. 


\section{- RESUMO}

Este texto tem como objetivo discutir o processo de criação de mashup vislumbrando os aspectos pedagógico-musicais imbricados nessa prática musical. Para tanto, parte da experiência de um músico produtor e dos trabalhos de Tobias $(2013 ; 2015)$, que relatam o trabalho com práticas de remix em aulas de música em escolas de educação básica. Os dados sobre o músico são provenientes de uma pesquisa de doutorado que investigou as aprendizagens que emergem das práticas de produzir e compartilhar música na cultura digital/participativa, tendo como campo empírico a experiência de três produtores musicais. Assim, esse texto se configura como um recorte da pesquisa, acrescido dos desdobramentos da mesma com experiências desenvolvidas em sala de aula em um curso de graduação em música.

\section{PALAVRAS-CHAVE}

Criação musical, mashup, edição sonora e aspectos pedagógicos.

\section{ABSTRACT}

This text aims to discuss the process of mashup creation glimpsing the pedagogicalmusical aspects imbricated in this musical practice. To do so, it is part of the experience of a producer musician and the work of Tobias $(2013,2015)$, who report the work with remix practices in music classes in elementary schools. The data about the musician comes from a doctoral research that investigated the learning that emerge from the practices of producing and sharing music in the digital / participatory culture, having as an empirical field the experience of three musical producers. Thus, this text is configured as a research cut, plus the unfolding of the same with experiences developed in the classroom in an undergraduate music course.

\section{KEYWORDS}

Musical creation; mashup; sound editing and pedagogical aspects. 


\section{Introdução}

Este texto discute o processo de criação de mashup vislumbrando os aspectos pedagógico-musicais imbricados nessa prática musical. O mashup consiste na junção e mistura de duas ou mais músicas formando uma nova composição. Para tanto, parte da experiência de um músico, Victor Hugo Mafra e dos trabalhos de Tobias (2013; 2014), que relatam o trabalho com práticas de remix em aulas de música em escolas de educação básica.

Os dados provenientes da prática musical de Victor Hugo fazem parte da tese de doutorado "Educação musical emergente na cultura digital e participativa: uma análise das práticas de produtores musicais" (Araldi, 2016) ${ }^{1}$, que investigou as aprendizagens que emergem das práticas de produzir e compartilhar música na cultura digital/participativa, tendo como campo empírico a experiência de três produtores musicais. Considerando a amplitude do campo da produção musical, participaram da pesquisa músicos que desenvolviam práticas relacionadas ao contexto da cultura digital e participativa, conforme proposto por Tobias (2013).

Essas práticas, segundo o autor, possibilitam direrentes engajamentos entre pessoas músicas e mídias. Como exemplos Tobias (2013) ressalta as versões cover, arranjos, paródias, sátiras, produções multipistas, remixes, produções baseadas em samples, mashups e tutoriais que são compartilhadas em mídias sociais como YouTube, Facebook, SoundCloud. O engajamento pode ser percebido nos comentários e postagens audiovisuais que trazem feedbacks, novas ideias e novas versões a partir das que são disponibilizadas, dentre outros fatores. Dessa forma, os trabalhos desenvolvidos por Tobias (2013) e Tobias et al (2015) no contexto pedagógico musical embasam teoricamente esse artigo.

A ideia de trazer esse recorte para este artigo nasceu, principalmente, com os primeiros desdobramentos da pesquisa, quando trabalhei esse tipo de prática musical nas aulas do curso de licenciatura em música que atuo². Sinalizo, especificamente, duas experiências: a primeira foi uma conversa via skype entre os estudantes da disciplina e o músico Victor Hugo, que pôde contar mais aspectos sobre sua prática musical. A segunda, foi um projeto desenvolvido por um dos estudantes, em uma disciplina que versa sobre tecnologia e educação musical, na qual pesquisou e buscou aplicativos para smartphones tendo como finalidade a criação de mashups, pensando, principalmente, o desenvolvimento com alunos de escolas de educação básica.

Essa experiência me levou, pela primeira vez, a tentar criar mashups também e me despertou ainda mais para desenvolver esse texto. Ressalto que a ideia de olhar mais a fundo sobre as pontecialidades desse tipo de produção sonora, que se faz a partir de edição sonora, se conecta com outra frente que venho desenvolvendo e pesquisando, que é a educação musical online, vislumbrando práticas como essa, como específicas das formas de fazer música dentro da cultura digital que estamos imersos. Essa discussão sobre o que é específico da tecnologia é abordada por Farias (2017), quando estuda sobre o eletrônico dos teclados.

Assim, para realizar a discussão aqui proposta, esse texto se divide em três

\footnotetext{
${ }^{1}$ PPGM-UNIRIO Orientação Professora Doutor José Nunes Fernandes

${ }^{2}$ Curso de Licenciatura em Música da Universidade Federal da Paraíba-UFPB
} 
partes: a primeira e a segunda tratam de contextualizar o mashup e trazer a prática de Victor Hugo, enfatizando as etapas de produção. A terceira parte traz um breve relato sobre desdobramentos desta pesquisa em sala de aula, com estudantes de um curso de licenciatura em música.

\section{O que é Mashup?}

O mashup, também conhecido como bootleg ou bastard pop,

é desenvolvido exclusivamente a partir de samples retirados de outras gravações e remixados para criar uma nova faixa. De maneira geral, apresenta amostras de duas ou mais canções, geralmente por diferentes artistas, editado em uma faixa através da manipulação de elementos como andamento, tonalidade. Um mashup muitas vezes apresenta os vocais retiradas de uma faixa justapostos com os instrumentais de outra ${ }^{3}$. (McGRANAHAN, 2010).

No que se refere ao uso de amostras (samples), o mashup é feito exclusivamente delas, diferente de gêneros como hip-hop, dance, dentre outros, cujos samples são combinados com novos conteúdos. Dessa forma, a utilização de gravações vai esbarrar nas questões de propriedade intelectual e direitos autorais dificultando que o mashup seja produzido com as autorizações dos autores. Tendo em vista esse contexto, em geral os interesses dos seus produtores fogem da esfera comercial, sendo disseminados em comunidades, pela internet e muito utilizados por DJs como recursos de pista. Para McGranahan (2010) o mashup "resume as mudanças na produção e na interação com a cultura popular. Os artistas de mashup utilizam tecnologia do computador para remixar, remodelar a cultura em seu entorno, além de construir e manter comunidades". Desse modo, apostam no mashup como vanguarda da música popular, tecnologia e direitos autorais.

O mashup pode ser considerado um gênero de remix. Para McGranahan (2010) o remix é "um termo que agrega todos os tipos de música que alteram gravações originais para criar novas versões, ou remixes, dessas gravações. ${ }^{5}$

\subsection{Como fazer mashup? Relatos a partir da prática de um DJ}

Victor Hugo, mora em Rio das Ostras, RJ, é Tecnólogo em Produção Fonográfica e trabalha como instrutor de informática em um Telecentro vinculado ao setor público, na zona rural da cidade. Sua relação com a música é principalmente na produção de mashups, re-edits, remixes, na atuação como DJ em festas e nos tra-

\footnotetext{
${ }^{3}$ No original: A mashup is a piece of recorded music that is comprised entirely of samples taken from other recordings and remixed to create a single new track. A standard mashup features samples from two or more songs, usually by different artists, edited into one track via the manipulation of elements like tempo, pitch, and key. A mashup often features the vocals taken from one track juxtaposed with the instrumentals taken from another.

${ }^{4}$ No original: epitomize current changes in the production of, and interaction with, popular culture. Mashup artists utilize computer technology to remix and reshape the culture around them, and to build and maintain community. [...] that the mashup genre and the worldwide community of its fans and producers are on the cutting edge of popular music, technology, and copyright.

${ }^{5}$ No original: Remix is an umbrella term that encompasses all types of music that alter original recordings to create new versions, or remixes, of those recordings.
} 
balhos de produção, gravação e ensino de produção em seu home studio. Ele coordena um fanzine e um evento mensal, com exibição de documentários relacionados à música, cujos temas contemplam, direitos autorais, mixagem, diferenças entre remix, reedit e mashup, diferenças entre áudio digital e analógico. Além desses projetos ele ministra workshops sobre edição de áudio.

Victor Hugo tem uma vasta produção de mashups e re-edits que compartiIha via internet e utiliza como recurso de pista nas festas que toca. Tendo em vista que o trabalho ocorre sem a autorização dos artistas e compositores, como no caso do remix, Victor enfatiza o trabalho que o mashup requer de quem está produzindo, "o mashup que eu digo é você ter que fazer na força, o cara não te dá nada separado, você pega a música já masterizada, e aí você vai meio que destroçar ela com a equalização, com a edição, pra conseguir encaixar na sua ideia que você tem com a outra música" (Victor Hugo, 27/07/15).

Como o mashup trabalha com a junção de duas músicas, a fala de Victor explicita que não se trata de apenas juntar uma música com a outra. O trabalho final depende de um amplo estudo e pesquisa para encontrar músicas que possam ser combinadas e, em seguida, realizar esses ajustes no som, no andamento, na tonalidade para formar uma nova composição. Victor relata: "quando eu comecei fazer mashup era difícil pra dedéu, então essa dificuldade me dava uma vontade de fazer, porque eu tinha que realmente cortar, recortar. Porque já que era uma dificuldade então eu corria atrás pra fazer" (Victor Hugo, 27/07/15). Aqui ele se refere principalmente ao software que utilizava na época, cujos recursos eram diferentes dos que ele utiliza atualmente.

Para facilitar o trabalho do mashup existem recursos como o "a capella", que consiste em faixas separadas apenas com a voz e a melodia principal de algumas músicas, material que é possível encontrar na internet. Na prática não costuma utilizar esses recursos que considera mais fáceis,

Porque pra mim mashup é quando você tira a força mesmo, o cara achou que estava com a obra concluída masterizada e aí você chega, pega e faz uma coisa diferente com outra música que outra pessoa fez. Você não teve essa facilidade do cara te entregar as pastas separadas ou então você achar na internet as pastas separadas. [...] 0 mashup é mais carrancudo, mais revoltado. (Victor Hugo, 27/07/15).

Nesse relato acerca do mashup, Victor aponta alguns traços de como costuma produzir. Quando afirma preferir fazer a música "a força", trabalhando com elementos musicais que já estão todos juntos na obra masterizada, Victor revela alguns conhecimentos musicais que estão implícitos nesse fazer musical. Como o trabalho se dá a partir da junção de duas músicas prontas, masterizadas, o esforço para enfatizar trechos, fazer com que elas juntas formem uma nova ideia, demanda encaixar ritmo, melodia, harmonia e as possíveis alterações no andamento para soar bem. Buscando analisar sob o ponto de vista pedagógico-musical, essa prática revela aprendizagens com relação aos elementos que constituem a música, o que pode ou não ser combinado demandando uma escuta atenta e pesquisa sonora constante. 
A escuta e pesquisa são enfatizadas por Tobias et al. (2015) quando defendem o potencial das tecnologias digitais em possibilitar engajamento entre pessoas, músicas e mídias. Os autores ressaltam que se tornou uma prática comum de alguns estudantes "recriarem ou modificarem músicas existentes a partir da sua própria estética e sensibilidade" (TOBIAS et al., 2015, p. 95).

\subsection{Como escolher as músicas?}

Tendo em vista que o mashup depende de músicas prontas, questionei Victor relata como escolhe as músicas. Para ele as primeiras ideias surgem por meio das batidas, tanto que pondera, "eu gosto muito de usar batidas, juntar... Eu não sou um cara de letra não, sou um cara de batida" (Victor Hugo, 28/05/14, grifos nossos). Ele exemplifica isso no mashup criado com as músicas "Juízo Final" de Nelson Cavaquinho e "I U She" da Peaches",

um dia comecei a escutar Nelson Cavaquinho eu fiquei com a música Juízo Final, e aquela batida que é de samba. Eu sabia de uma música eletrônica que tinha exatamente essa batida. Aí eu juntei elas pela batida, mas depois que eu fui ver, elas se ligavam. Até a própria foto demonstra isso, eles trocam uma ideia. A Peaches, esquerda na foto é homossexual e a letra da música (I U She) no mashup com a juízo final ela canta "eu não tenho que fazer escolhas, eu gosto de meninos e meninas". Essa foto do Nelson tendenciosamente mostrando um pintinho pode ser interpretada: "Na minha época não tinha nada disso não!” Seria o Juízo Final! (Victor Hugo, 28/05/14).

A foto mencionada no relato pode ser visualizada na Figura 1 que traz 0 layout da divulgação da música na plataforma SoundCloud

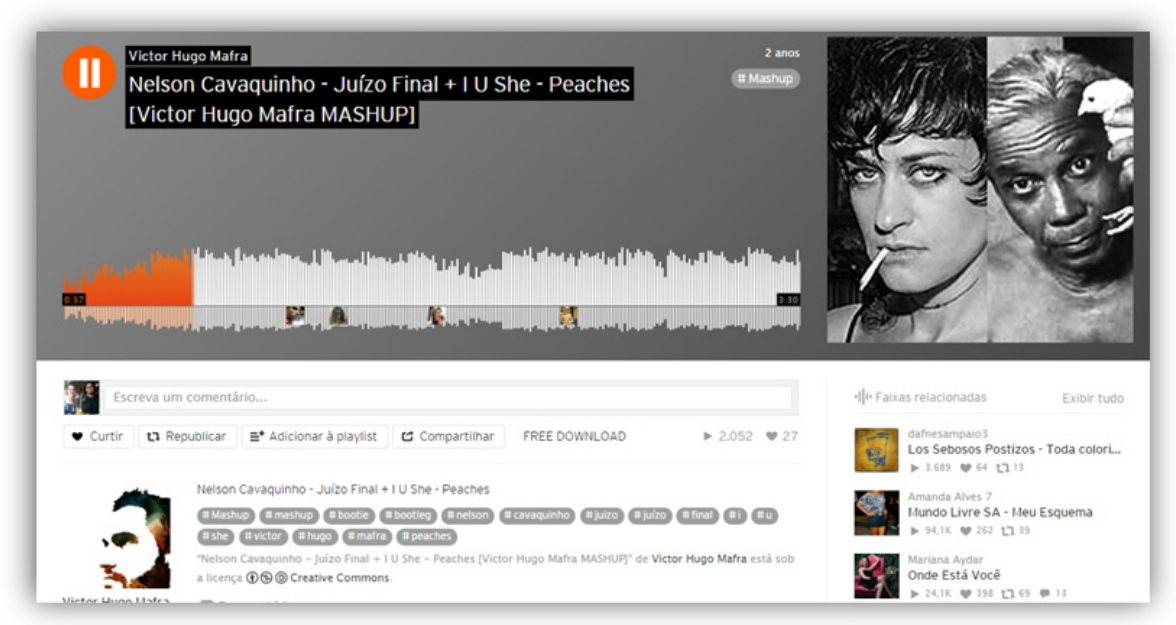

Figura 1. Mashup "Nelson Cavaquinho +Peaches" no SoundCloud; Print do SoundCloud.

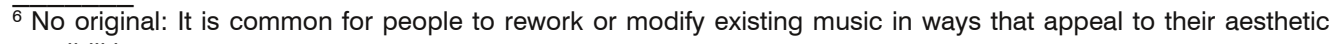
sensibilities.

${ }^{7}$ Link para ouvir: https://soundcloud.com/victorhugomafra/nelson-cavaquinho-ju-zo-final 
Nesse detalhamento pode-se presumir que, mesmo partindo das batidas, aparecem mais elementos até então subjetivos que se interligam na nova composição. Desse modo, Victor declara: "mais pra frente eu comecei a fazer com esse propósito mesmo, a de misturar os pontos ou subjetividades das músicas. A do Chico Science com a Orquestra Armorial, que o Chico fala é o povo na arte e a arte no povo ${ }^{8}$. Eu fiz isso quando estava tendo aqueles protestos em 2013. E aí já comecei a ligar, pegar as duas como proposta e fazer" (Victor Hugo, 28/05/14). Esta foi "a única que eu fiz de mashup com intuito da letra dizer alguma coisa" (Victor Hugo, $27 / 07 / 15)$. Isso pode ser visto na forma como ele explicou a música dentro da plataforma SoundCloud.

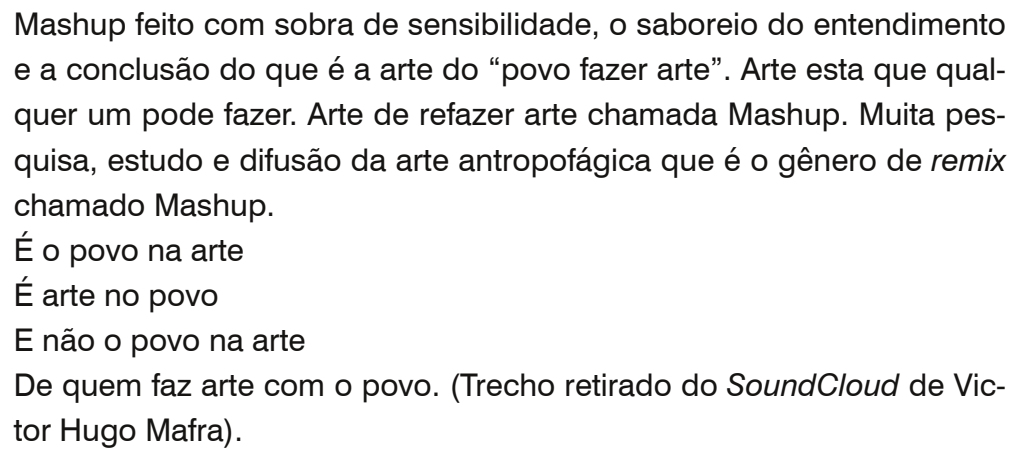

Esse exemplo retrata o objetivo que Victor teve com esse mashup que foi enfatizar um trecho da letra que pudesse transmitir uma mensagem. As manifestações de junho de 2013 representaram uma grande mobilização do povo brasileiro que foi às ruas para solicitar mais transparência aos governantes, pedidos em prol da saúde e educação e de uma mudança na política brasileira, representada sempre pelas mesmas oligarquias. Na explicação que Victor faz sobre o mashup ele salienta a mensagem que pretendeu passar e traz os sentidos do mashup como "Arte de refazer arte".

Com a expressão "Arte de refazer arte" Victor enfatiza o que está no centro das práticas de criações musicais a partir de músicas prontas como mashup e remix. As aprendizagens imbricadas nas práticas de mashup são ressaltadas por Tobias (2013) ao enfatizar a importância de refletir sobre: "como essas duas músicas se relacionam? Por que você tomou essa decisão? Quais aspectos da música original você enfatizou ou modificou? Como essa música é representativa do gênero que você escolheu para usar? 9" (TOBIAS, 2013). Essas questões perpassam a escuta musical atenta, as escolhas das músicas que dependem de conhecimentos sobre tonalidade, estrutura da música, ou então sobre significados das letras, como o exemplo citado por Victor Hugo.

O fato de Victor salientar o trabalho que demanda "muita pesquisa, muito estudo" está relacionado às escolhas que são necessárias na criação desse tipo de produção. Isso porque é fundamental o elo de ligação entre as duas músicas e os

\footnotetext{
${ }_{8}^{8}$ Link para ouvir: https://soundcloud.com/victorhugomafra/orquestra-armorial-galope

${ }^{9}$ No original: How do these two songs relate? Why did you make that decision? What aspects of the original are you highlighting or changing? How is this representative of the particular genre you chose to use?
} 
elementos que elas compartilham. Há que estar atento à viabilidade e por isso é importante "esse acervo mental de juntar uma com a outra, saber que dá possibilidade pelo tempo dela, pela batida" (Victor Hugo, 27/07/15). Nesse jogo de possibilidades ocorrem também coincidências.

Victor Hugo: Tem também as coincidências, claro que a do Crioulo com o Planet Hemp foi uma feliz coincidência que aquele órgão, tem gente que hoje em dia não acredita que foi possível fazer aquilo. Músicos já conceituados que disseram, não é possível10! Pesquisadora: E era o que já tinha na música mesmo? Victor Hugo: Era, eu não tirei nada, eu só dei uma cortadinha repeti o baixo de novo do Mariô, mas basicamente só encaixei. A do Frank Sinatra também com o Black Milk ${ }^{11}$, que foi outra sorte. (Victor Hugo, 07/07/14).

Victor sinaliza outro fator que contribui para a concepção e desenvolvimento das músicas que "são as sacadas. Geralmente a questão de misturar duas músicas ou rearrumar uma música é intuitiva, digo isso, pois muitos dos meus mashups foram instintivos, mas eu percebia enquanto produzia e depois realçava a sacada" (Victor Hugo, 07/07/14; grifos nossos). Esse é um exemplo emblemático de que as primeiras etapas de produção, concepção da ideia e desenvolvimento, ocorrem continuamente sendo os detalhes e novos elementos revelados no momento em que as músicas passam a soar juntas. Nesse contexto estão reunidos os conhecimentos sobre produção e novas aprendizagens que surgem da apreciação mais direcionada nos detalhes que vão fazer diferença na nova composição.

Nesses detalhes estão conhecimentos acerca de tonalidade, estilo musical, melodia/acompanhamento, dentre outros elementos musicais que revelam os aprendizados que esses músicos/produtores vão construindo por meio dessa prática. Tais aprendizados são discutidos por Tobias et al. (2015) ao elencar o potencial pedagógico no trabalho com a prática de remix em aulas de música, nas quais os alunos, reunidos em pequenos grupos, produziram um remix a partir das composições dos outros grupos. Com essa atividade eles "ouviram e analisaram a música original criticamente; se tornaram conscientes sobre o tom, timbre e afinação das suas próprias vozes e como essas qualidades se conectam e interagem com as escolhas e ideias trazidas por outros músicos ${ }^{12 "}$ (TOBIAS, et al., 2015, p. 96). Este exemplo de atividade integra práticas coletivas na cultura digital e participativa.

\subsection{Autoria na criação de mashups e re-edits}

Ao falar sobre a característica dos seus mashups e re-edits Victor Hugo traz a experiência de juntar músicas de períodos diferentes. Como começou a produzir mashups em 2011, ele considera que ainda está definindo o seu estilo, mas avalia que é diferente do que se faz normalmente "nessa cultura do mashup" que consiste

\footnotetext{
$\overline{{ }_{10}}$ link: https://soundcloud.com/victorhugomafra/criolo-mario-hemp_mario

11 link: https://soundcloud.com/victorhugomafra/victor-hugo-mafra-good-year-black

${ }^{12}$ No original: Through their remixing, students listened to and analyzed the original music critically; they became aware of the tone, timbre, and pitch of their own voices and how those qualities connected to and interacted with other musicians' choices and ideas.
} 
em "juntar uma Cristina Aguillera com outra música mais pop ainda" (Victor Hugo, 28/05/14). A partir do contato com um produtor musical do Rio de Janeiro, Fabiano, que disse que a sua linha de som é "o que ele chama de mashup cultural. Que é diferente do que o pessoal produz de mashup" (Victor Hugo, 28/05/14), Victor começou a perceber que o seu trabalho vai na contra mão do que é mais comum na cultura mashup, no entanto, foi esse diferencial que chamou a atenção do Fabiano, "eu sigo outra linha. E eu só consegui essa do Juízo Final por causa que eu juntei com uma coisa semi-pop que é a Peaches, mas ele se amarrou na minha por causa disso" (Victor Hugo, 28/05/14). De acordo com Jenkins et al. (2006, p. 33), os trabaIhos com mixagens envolvem "uma criativa justaposição de materiais que pertencem a nichos culturais diferentes".

A ideia de trazer músicas mais antigas é para ele um meio para que essas músicas sejam ouvidas dentro de outro contexto, alcançando um público diferente,

Mas agora eu tô vendo esse propósito em mim que é pegar essas coisas antigas. Por exemplo, eu fiz o re-edit do Meu Caro Amigo ${ }^{13}$, do Chico e o seu Valdir morreu no ano passado, no mês de setembro. $E$ tá, eu já to vendo que tô querendo pegar essas coisas antigas e dar uma nova roupagem. Tipo assim, muita gente vai escutar o seu Valdir tocando cavaquinho porque eu tô misturando com o trap music que é um estilo novo. A trap music tá na moda e esse tipo de música tem muitas pessoas que escutam. Então fazer essa ponte da velharia, vamos dizer assim, do passado pra agora. Eu tô me vendo mais nessa função. (Victor Hugo, 28/05/14).

Nesse relato Victor está mostrando o potencial da sua música em alcançar outros públicos e interligar músicas que fazem parte da sua própria escuta, com as músicas que fazem parte da tendência atual. Esse trânsito por diferentes estilos e épocas permite que ele faça músicas atendendo aos pedidos de amigos, como por exemplo, "a do Piazzolla14 foi um amigo meu que pediu. Eu sabia que ele gostava de funk e eu não conhecia Piazzolla. Aí eu peguei o Piazzolla e botei um 'funkão' pra ele. Eu peço pra que as pessoas falem a música e eu entro com a minha" (Victor Hugo, 28/05/14; grifos nossos).

Ainda sobre as misturas de diferentes músicas, Victor traz uma experiência que viveu dentro de casa, "tenho um bom exemplo dentro de casa que foi mexer com uma música do Nelson Gonçalves que meu pai tanto escuta - e logo eu acabo escutando e gostando - com uma música do meu gosto, de um estilo totalmente moderno e totalmente aversa ao gosto do meu pai, mas que no final soou bem e ambos curtiram" (Victor Hugo, 07/07/14).

Tal possibilidade, sob o ponto de vista pedagógico, demonstra o potencial de trabalhar a diversidade de repertórios presente em uma sala de aula a partir das preferências musicais dos alunos. Trata-se de tornar possível o trabalho de juntar músicas diferentes e fazê-las conversar, envolvendo assim escutas compartilhadas, trabalho em equipe. Tais aspectos pedagógicos são discutidos por Tobias et al. (2015) enfatizando que a diversidade de músicas que são ouvidas para poder com-

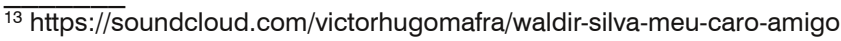

14 https://soundcloud.com/victorhugomafra/astor-piazzolla-los
} 
binar nos mashups, os estudos acerca de gêneros musicais que podem fazer parte de um remix, permite um trabalho musical diversificado em sala de aula. Neste trabalho as preferências musicais dos alunos terão espaço na escola e as atividades em grupo e a ideia de compartilhar dentro e fora da sala de aula possibilitam a ampliação do repertório musical.

\section{Sobre experiências em sala de aula - possíveis desdobramentos}

Os primeiros desdobramentos da pesquisa ocorreram de duas experiências: a primeira foi a participação de Victor Hugo, via Skype, em uma aula da disicplina Metodologia V (turma 2016.1). As principais questões dos alunos para Victor giraram em torno do processo de criação dos mashups. Nesse sentido, Victor trouxe dados novos, que não estão na tese, acerca das possibilidades de fazer mashup ao vivo, como recurso de pista. Assim, ele deixou de gravar e colocar nas redes. O que ele faz é disponibilizar o set inteiro, contendo muitos mashups que são feitos no momento e para aquele momento específico. Nesse sentido, os alunos ressaltaram os conhecimentos musicais que Victor mobiliza para fazer essas junções, além de outras curiosidades sobre o processo de criação.

A segunda experiência ocorreu também na disciplina Metodologia $\mathrm{V}$, mas na turma de 2017.2. Um dos alunos desenvolveu seu projeto pensando no trabalho com mashups utilizando apenas aplicativos para smartphones, considerando, principalmente, o uso desse aparelho pelos adolescentes e jovens alunos. Para tanto, o aluno desenvolveu uma ampla pesquisa para encontrar aplicativos que fossem acessíveis. Além disso, trouxe uma junção de aplicativos para edição de áudio, mudança de tonalidade e sincronização de andamento, que se tornaram necessários para a produção do mashup. Ele ministrou uma oficina para os demais estudantes da disciplina, ensinando como utilizar os aplicativos. Consideramos que o tempo foi curto para a realização da prática em si, mas surgiram várias ideias da turma, além da descoberta de mais alguns aplicativos que podem ser utilizados. Como desafio, surgiu também uma questão estrutural, pois nem todos os celulares conseguem rodar os aplicativos de edição de áudio. Fato esse que, também, precisa ser ponderado quando se tratar de trabalhos em sala de aula. Essa prática possibilitou que a turma buscasse músicas com a mesma tonalidade (para não precisar editar), que tivessem harmonias que combinassem, procurasse músicas com faixas já separadas (o que não é tão fácil para quem não constuma transitar por esses sites). Assim, mesmo não tendo produtos finais, foi lançado mais um desafio e a prática mostrou as potencialidades dessa forma de produção musical.

\section{Considerações finais}

Este texto é o primeiro exercício que realizo buscando discutir sobre os desdobramentos da pesquisa nas minhas aulas no curso de graduação em música que trabalho. São pequenas ações que mostram o potencial dessa atividade, mas que ainda necessitam de outras experiências para consolidar alguma proposta prática.

No entanto, mesmo com experiências iniciais, vislumbro na produção de mashups possibilidades de realização de práticas online e semipresenciais que se 
conectam diretamente com a forma de fazer música na contemporaneidade. Práticas essas que muitos dos nossos alunos podem estar fazendo, mas que nem sempre encontram eco nas aulas de música em espaços sistematizados. Com essa prática vislumbro o que Farias (2017) discutiu em relação ao teclado, considerando que as diferentes tecnologias propiciam outras formas de fazer música e, nesse contexto, articulando com Tobias (2013), vimos nas práticas musicais da cultura digital, como o mashup, um potencial para outras aprendizagens musicais.

\section{REFERÊNCIAS}

ARALDI-BELTRAME, Juciane. Educação musical emergente na cultura digital e participativa: uma análise das práticas de produtores musicais. 2016. Tese (Doutorado em Música) - Programa de Pós-Graduação em Música, Universidade Federal do Estado do Rio de Janeiro, Rio de Janeiro, 2016.

FARIAS, Maria Amélia Benincá de. O "Eletrônico" do "Teclado": Questões da Tecnologia da Música para a Performance e a Educação Musical. In: XI CONFERÊNCIA REGIONAL LATIONO-AMERICAN DE EDUCAÇÃO MUSICAL DA ISME. 2017, Natal. Anais... Natal - RN.

TOBIAS, E. Toward Convergence: Adapting Music Education to Contemporary Society and Participatory Culture. Music Educators Journal, v. 99, n. 4, p. 29-36, June, 2013.

TOBIAS, E; VANKLOMPENBERG, A.; REID, C. Reflecting on changes in practice through integrating participatory culture in our classrooms. Mountain Lake Reader: Conversations on the study and practice of music teaching, v. 6 , p. 94-110, 2015.

Recebido em 28/02/2019 - Aprovado em 18/ 03/2019

Como citar:

BELTRAME, J. A. (2019) "Criar novas ideias a partir de músicas prontas": reflexões, experiências e aprendizagens na produção de mashu. OuvirOUver, 15(1), 60-70. https://doi.org/10.14393/OUV24-v15n1a2019-4 